J. Dairy Sci. 92:1317-1318

doi:10.3168/jds.2009-2143

(c) American Dairy Science Association, 2009.

\title{
Journal of Dairy Science 2008 Editorial Report
}

\author{
Gary W. Rogers, Editor-in-Chief \\ Geno Global, Hamar, Norway and New Market, TN 37820
}

The Journal of Dairy Science (JDS) had another very successful year in 2008. The outstanding staff members at ADSA headquarters and the senior editors and section editors are to be congratulated on another fantastic job in 2008. The staff members that work on JDS are extremely efficient and very professional in their work. I would especially like to acknowledge the efforts of Susan Pollock, the managing editor of JDS and FASS director of editorial and production, and Louise Adam, who is one of several technical editors of JDS and assistant director of editorial and production. They do an excellent job of keeping me informed of new issues on the publishing front, and they make sure that each edition of JDS is ready in a timely fashion. Jeremy Holzner should also be recognized for his contributions to the publication process as he coordinates the efforts on Manuscript Central. Gayle Gleichman and Sharon Frick (production coordinators), Ted Veatch (figure processor), and Lisa Krohn, Susan Krusemark, Mandy Maiden, and Ron Keller (technical editors) all help to maintain the high quality of JDS.

\section{Impact Factor}

The Journal of Dairy Science continues to be the best scientific journal that serves the international community of dairy scientists. The impact factor for JDS from the most recent Institute for Scientific Information report is 2.361 , which is the third-highest impact factor among 47 major journals in the category of agriculture, dairy, and animal science. The impact factor is based primarily on journal citation reports. Animal Genetics and Domestic Animal Endocrinology are the only journals in the category that have higher impact factors, and their impact factors (2.640 and
2.528 , respectively) are only slightly higher than that for JDS. The outstanding impact factor for JDS reflects the dedication and hard work of the authors, reviewers, editors, and staff who work on JDS.

\section{Journal Statistics}

In 2008, JDS published a total of 517 articles and 5,134 pages (Tables 1 and 2), making 2008 the sixth year in a row that JDS has published more than 400 manuscripts and more than 4,000 pages. In 2008, we published 480 research papers, 33 Our Industry Today papers, and 4 Invited Reviews. We did not meet our target of 10 to 12 reviews in 2008. We need to improve in this area in the coming year, and a call for suggested topics and authors has been made to ADSA members.

The largest section in JDS in 2008 was Physiology and Management (PM) with 160 research papers (Table 3). The second largest section was the Nutrition, Feeding, and Calves (NFC) with 143 research papers. The Dairy Foods (DF) section and the Genetics and Breeding (GB) section published 81 and 99 research papers, respectively.

Of the article types other than full-length research papers or Our Industry Today papers, Short Communications were most frequent. In 2008, JDS published 27 Short Communications, 6 Technical Notes, and 6 Letters to the Editor.

The total time from receipt of a manuscript until final publication in JDS continues to be outstanding. In 2008, the average time in review for accepted papers was $141 \mathrm{~d}$, and the average time from acceptance until the papers were ready for posting and printing was 92 d. It takes about $10 \mathrm{~d}$ to get the posting completed so total average production time after acceptance was 102

Table 1. Journal of Dairy Science statistics for 2008 compared with previous years

\begin{tabular}{|c|c|c|c|c|c|c|c|c|c|c|}
\hline & 2008 & 2007 & 2006 & 2005 & 2004 & 2003 & 2002 & 2001 & 2000 & 1999 \\
\hline Avg. papers received/mo & 85 & 79 & 74 & 76 & 65 & 56 & 53 & 50 & 44 & 42 \\
\hline Avg. papers accepted/mo & 48 & 46 & 46 & 42 & 39 & 38 & 37 & 31 & 30 & 28 \\
\hline Avg. papers published/mo & 44 & 52 & 45 & 40 & 40 & 38 & 33 & 30 & 29 & 28 \\
\hline Pages published & 5,134 & 5,849 & 4,961 & 4,451 & 4,562 & 4,341 & 3,633 & 3,091 & 3,413 & 2,944 \\
\hline Average review time (d) & 141 & 127 & 125 & 122 & 132 & 105 & 121 & 158 & 158 & 180 \\
\hline Average production time (d) & 102 & 106 & 126 & 92 & 135 & 151 & 159 & 125 & 137 & 115 \\
\hline Average total time $(\mathrm{d})$ & 243 & 233 & 251 & 214 & 267 & 256 & 280 & 283 & 295 & 295 \\
\hline
\end{tabular}


Table 2. Journal of Dairy Science manuscript and page statistics by article type for 2008

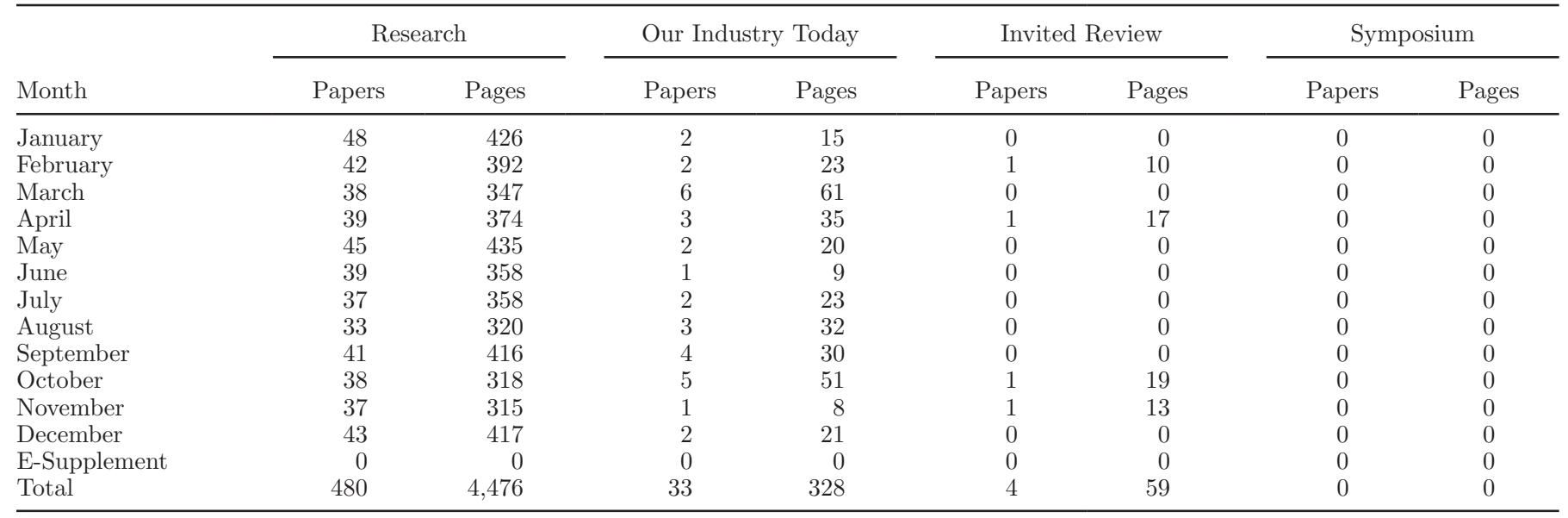

d. The average time from submission to publication for an accepted paper was $243 \mathrm{~d}$ in 2008.

Another important statistic for JDS is the time that it takes to get the first decision on a paper. The average time from submission to the first decision is less than $44 \mathrm{~d}$.

The rate of new submissions to JDS continues to be outstanding. In 2008, JDS had 1,024 (compared with 944 in 2007) new articles submitted for consideration. In addition, 1,200 revised papers were submitted. The total number of manuscripts handled by our senior editors and section editors in 2008 was 2,224! Journal submissions also reflect the international nature of our journal. In 2008, $31 \%$ of new submissions (318 manuscripts of 1,024) were from the United States and $8.4 \%$ (86) were from Canada. The number of new submissions in 2008 from Spain ranked third (54).

The Journal of Dairy Science functions currently with 5 senior editors and 10 section editors. Mike Schutz (GB) was the only retiring editor for 2008; he was replaced by Georgios Banos. In addition, Rupert Bruckmaier joined the team as a section editor in PM. Five of the 15 senior and section editors are from outside the United States (33\%). It should be noted that all 3 of the section editors in GB are from outside of the United States.

I would like to thank the editorial board and the very large number of ad hoc reviewers for their service to JDS this past year. The timely and dedicated effort provided by the editorial board and the ad hoc reviewers is essential to maintaining the reputation of JDS, and the efforts of these reviewers are greatly appreciated. Ten editorial board members completed their final term during 2008 and we have new members for 2009 . Thirteen of the $59(22 \%)$ editorial board members are from outside the United States.

The current Journal Management Committee (JMC) is chaired by John Bernard. Other members of the current JMC are John Lucey, Tom Greutzmacher, and Jesse Goff.

Table 3. Journal of Dairy Science research manuscripts and page statistics by science section ${ }^{1}$ for 2008

\begin{tabular}{|c|c|c|c|c|c|c|c|c|}
\hline \multirow[b]{2}{*}{ Month } & \multicolumn{2}{|c|}{$\mathrm{DF}$} & \multicolumn{2}{|c|}{$\mathrm{PM}$} & \multicolumn{2}{|c|}{$\mathrm{NFC}$} & \multicolumn{2}{|c|}{ GB } \\
\hline & Papers & Pages & Papers & Pages & Papers & Pages & Papers & Pages \\
\hline January & 9 & 84 & 13 & 117 & 13 & 120 & 13 & 105 \\
\hline February & 9 & 89 & 12 & 102 & 13 & 121 & 8 & 80 \\
\hline March & 10 & 99 & 13 & 122 & 10 & 97 & 5 & 29 \\
\hline April & 4 & 35 & 11 & 109 & 17 & 171 & 7 & 59 \\
\hline May & 7 & 69 & 15 & 135 & 17 & 176 & 6 & 55 \\
\hline June & 4 & 31 & 16 & 165 & 12 & 108 & 7 & 54 \\
\hline July & 8 & 60 & 9 & 89 & 12 & 130 & 10 & 81 \\
\hline August & 6 & 67 & 13 & 127 & 6 & 54 & 8 & 72 \\
\hline September & 1 & 14 & 19 & 187 & 13 & 133 & 8 & 82 \\
\hline October & 7 & 70 & 14 & 117 & 9 & 75 & 8 & 56 \\
\hline November & 6 & 54 & 8 & 66 & 7 & 63 & 16 & 132 \\
\hline December & 10 & 98 & 17 & 141 & 14 & 153 & 3 & 31 \\
\hline Total & 81 & 770 & 160 & 1,477 & 143 & 1,401 & 99 & 836 \\
\hline
\end{tabular}

${ }^{1} \mathrm{DF}=$ Dairy Foods; PM = Physiology and Management; NFC = Nutrition, Feeding, and Calves; and GB = Genetics and Breeding. Table does not include Our Industry Today manuscripts, invited reviews, or symposium papers. 